\title{
Experimental Validation of Fatigue Life of CCGA 624 Package with Initial Contact Pressure of Thermal Gap Pads under Random Vibration Excitation
}

\author{
Tae-Yong Park $\mathbb{D}^{\mathrm{D}},{ }^{1}$ Su-Hyeon Jeon $\mathbb{D}^{\mathrm{D}},{ }^{2}$ Su-Jeong Kim $\mathbb{D}^{\mathrm{D}},{ }^{2}$ Sung-Hoon Jung, ${ }^{3}$ \\ and Hyun-Ung $\mathrm{Oh} \mathbb{1}^{1}$ \\ ${ }^{1}$ Space Technology Synthesis Laboratory, Department of Aerospace Engineering, Chosun University, 309 Pilmun-daero, Dong-gu, \\ Gwangju City 61452, Republic of Korea \\ ${ }^{2}$ LIG Nex1 Co. Ltd., 207 Mabuk-ro, Giheung-gu, Yongin City, Gyeonggi-do 16911, Republic of Korea \\ ${ }^{3}$ Agency for Defense Development (ADD), Postoffice Box 35, Yuseong-gu, Daejeon City 34186, Republic of Korea
}

Correspondence should be addressed to Hyun-Ung Oh; ohu129@chosun.ac.kr

Received 20 April 2018; Revised 16 July 2018; Accepted 5 August 2018; Published 8 October 2018

Academic Editor: Paolo Gasbarri

Copyright (C) 2018 Tae-Yong Park et al. This is an open access article distributed under the Creative Commons Attribution License, which permits unrestricted use, distribution, and reproduction in any medium, provided the original work is properly cited.

\begin{abstract}
Thermal gap pads are widely used for effective heat transfer from high-heat-dissipating components to a heat sink. The initial contact pressure of thermal pads is an important parameter for enhancing the heat transfer capability of thermal design during the assembly process of the heat sink. However, this causes stress on the solder joint of the component as a result of the pad's inherent resistance to deformation. In this study, we investigated the effect of thermal pad on the fatigue life of the solder joint of CCGA 624 package for space usage. A random vibration fatigue test for several specimen assembly sets with various pressurization levels of thermal gap pads was performed, and their fatigue lives were compared with that of the package without the initial pressure of thermal gap pads.
\end{abstract}

\section{Introduction}

Highly integrated electronic packages such as a ball grid array (BGA), small outline package, and column grid array (CGA) offer several advantages for space applications owing to a drastic reduction in size and weight and efficient utilization of accommodation area of a printed circuit board (PCB) [1-3]. These packages are subjected to various forms of mechanical loads during the launch phase, such as a quasistatic load due to the engine thrust, a sine vibration due to the main engine cut-off (MECO) and pogo oscillation, a random vibration due to the noise of the exhaust, turbulent flows along the launcher, and shock loads induced by the activation of the pyro-device [4]. In addition, these packages are also subjected to thermal stresses due to a mismatch between the thermal expansion coefficients of the different materials of the electronic equipment, induced by the on-orbit thermal cycling environment. Among these, random vibration is a main cause of failure in electronics [5] because a relative displacement between the package and PCB due to the repetitive bending behavior of the PCB incurs a fatigue fracture on a solder joint, which connects the package to the PCB.

Several previous studies have focused on securing the mechanical safety of a solder joint under vibration excitation by applying mitigation techniques to the package, such as applying an underfill or dummy solder balls [6-8]. Kim and Hwang [6] investigated the effect of underfill on the fatigue life of a plastic ball grid array (PBGA) package for space usage under random vibration excitation of the launch. Fatigue test results indicated that the underfill remarkably improved the structural safety of the solder joint by reducing its stress under random vibration. Jang et al. [7] investigated the effect of dummy solder balls on the fatigue life of a solid-state drive (SSD) under harmonic vibration excitation. The dummy solder balls replaced the functional solder balls at the outmost corners of the package that were vulnerable to the vibration environment. The results of the fatigue test under harmonic vibration 
showed that applying dummy solder balls improved the fatigue life of the given SSD by 4.5 times by reducing the stresses on the functional solder balls. Uppalapati et al. [8] investigated the sensitivity of three critical PCB design factors on the mechanical safety of the solder joint of a flip-chip ball grid array under vibration during shipping. The results showed high sensitivity with respect to the location of the package on the $\mathrm{PCB}$, trace routing orientation of the PCB under the package, retention mechanism design, and mass of the heat sink.

These highly integrated electronics with higher component density and advanced functional capability generate considerable heat during their operation. Thus, a proper thermal management of high-heat-dissipating packages is important to prevent failure of spaceborne electronics used in a severe space thermal environment. In general, thermal gap pads act as essential hardware for heat sink implementation by enabling heat transfer path between the high-heatdissipating packages and a heat sink to avoid an excessive increase in temperature during their operation $[8,9]$. The heat transfer capability of the thermal pads can be enhanced by controlling the initial contact pressure level of the pads during the assembly process of heat sinks. For example, the thermal conductivity of thermal gap pads (THERM-A-GAP G579, Parker Chomerics Co.) with 50\% deflection in thickness direction is 1.23 times higher than that of the pads with $10 \%$ deflection [10]. This deflection allows the thermal pads to effectively maximize the rate of thermal transfer by filling both micro- and macrogaps between the components. However, the high pressure induced by the deflection of the pads also causes stress on the solder joint of the component. Bruzda [11] performed stress-strain measurements for several sets of pad assembly conditions to determine the extent to which they affected the stress levels reached during the test. The results showed that stress can be controlled by modifying the assembly process to take advantage of the stress relaxation properties of the pads and design to allow unimpeded lateral movement of the pad. Chiu et al. [12] investigated the effect of compression load of thermal pads on the fatigue life of a BGA solder joint under a thermal cycling environment. The results of the thermal cycling test and finite element analysis showed that the fatigue life of the solder joint drastically decreased depending on the level of compression load due to the acceleration of creep behavior of a solder ball. Lee [13] measured the thermo-mechanical creep and stress relaxation properties of silicone thermal gap pads through experimental tests using a dynamic mechanical analysis. The experimental results showed that stress relaxation resistance can be reduced by controlling silicone chemistry.

On the other hand, the initial contact pressure of the pad might be advantageous in terms of securing the structural safety of the solder joint of the component in a vibration environment by restricting the displacement of the component. However, this has not yet been investigated in the previous studies. Therefore, in this study, we focus on the effect of the initial pressure level of the thermal gap pads from the viewpoint of fatigue life of the solder joint of the packages under a random vibration environment. For the experimental

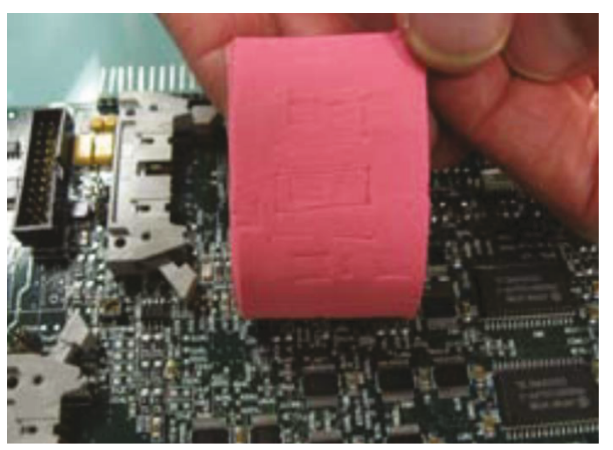

FIgURE 1: Configuration of the THERM-A-GAP G579 thermal gap pad [17].

validation, the PCB test specimens of CCGA 624 packages with various pressure levels of $0 \%, 10 \%$, and $50 \%$ for the thermal pads were manufactured and exposed to random vibration excitation until the daisy-chain resistance of each specimen exceeded the failure criteria. The test results indicated that the initial contact pressure level of the thermal pads affected the time to failure of the solder joints. In addition, the time to failure was predicted by structural analyses of tested specimens for investigating which phenomenon is the most dominant in affecting the fatigue life of the solder joint. The remainder of this paper is organized as follows. In Section 2, an overview of the thermal design for CCGA 624 packages using thermal gap pads is described. In Section 3, a detailed description of the PCB specimen for the fatigue test is given. In Section 4, validation of the test results, including crosssectional micrographs of the solder joints of the tested CCGA packages and structural analysis results, are given. In Section 6, some concluding remarks are given.

\section{Application of Thermal Gap Pads}

Highly integrated packages such as CCGA packages have attracted considerable attention in the aerospace engineering field, as well as various other fields such as military and commercial electronics, because of the ever increasing demand to improve functionality and compactness of electronic equipment [14-16]. However, these packages typically generate higher amount of heat compared to the conventional packages developed in earlier generation due to their high degree of integration. Therefore, an efficient thermal control is essential to preventing package failure caused by excessively high temperatures during operation. The thermal gap pad shown in Figure 1 is a thermal hardware that is widely used for thermal control of high-heat-generating packages. Figure 2 shows an example of the thermal design of the CCGA624 package with the thermal pad, which is placed between the package and heat sink to provide a heat transfer path to reject the heat away from the package. The thermal conductivity value of the pad can be controlled by adjusting its compression ratio in the thickness direction through the heat sink design. The pad used in this study is THERM-AGAP G579 of Parker Chomerics [17] and satisfies an outgassing requirement for space use. The specifications of the pad are listed in Table 1. 


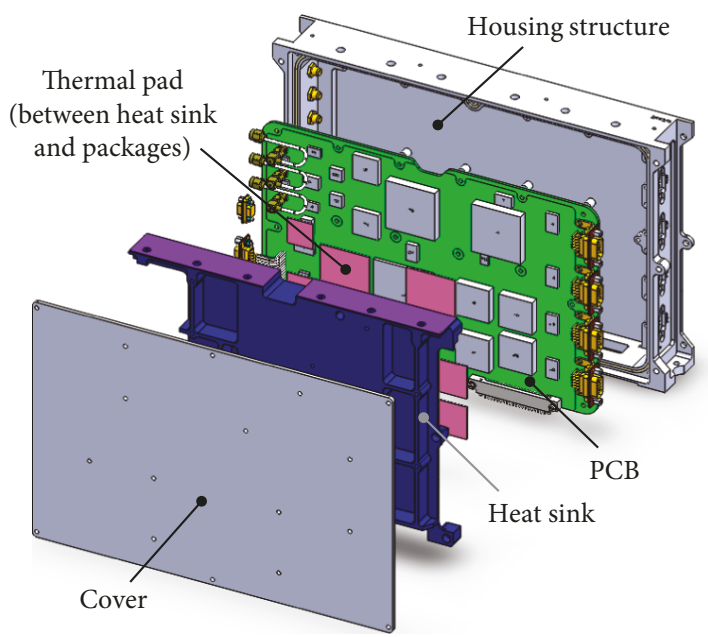

Figure 2: Example of thermal design for electronics using the thermal gap pad.

Figure 3 shows variations in thermal impedance value and compressive load of the thermal pad in accordance with its compressive ratio until the maximum value of $50 \%$ guaranteed by the manufacturer is reached. To enhance the heat transfer capability, the thermal impedance value can be reduced from $4.89^{\circ} \mathrm{C} \cdot \mathrm{cm}^{2} / \mathrm{W}$ to $2.2^{\circ} \mathrm{C} \cdot \mathrm{cm}^{2} / \mathrm{W}$ by compressing the pad. Figure 4 shows an example of the temperature contour maps of an electronic package with thermal gap pad applications, as shown in Figure 2, for a compression ratio of $0 \%$. Table 2 presents the maximum temperatures of the CCGA package with pad compression ratios of $0 \%, 10 \%$, and 50\%, respectively. On-board equipment faces the qualification campaign to ensure the complete reliability during a mission lifetime. The thermal qualification is performed by cycling the equipment in a temperature range obtained by adding a temperature margin (positive and negative) to the nominal operating thermal range (design temperatures). The results with compression ratio of $0 \%$ show that the maximum temperature of the CCGA package is $144.5^{\circ} \mathrm{C}$. By applying compression ratios of $10 \%$ and $50 \%$ to the thermal pad, the package temperature can be reduced to $72.53^{\circ} \mathrm{C}$ and $69.71^{\circ} \mathrm{C}$, respectively. These results indicate that a more effective heat transfer can be achieved by increasing the compression ratio of the thermal pad, although only $2.82^{\circ} \mathrm{C}$ of temperature reduction can be obtained with $50 \%$ compression ratio as compared to the $10 \%$ ratio. However, the compression ratio of $50 \%$ requires a compressive static load of $82.37 \mathrm{~N}$ on the pad, which is 11.7 times higher than that required by the $10 \%$ ratio, as shown in Figure 3 . Therefore, in this study, we investigated the effect of the initial compressive static load of the pad from the viewpoint of fatigue life of the solder joint under a random vibration environment.

\section{CCGA624 PCB Specimen and Fatigue Test}

3.1. Description of PCB Specimen. To investigate the effect of initial pressure level of the thermal gap pad on the fatigue life of the solder joint under a random vibration environment, the PCB specimens with the CCGA624 package shown in
Figure 5 were manufactured. A CCGA package was mounted on the center of the PCB formed of FR-4 with dimensions of $100 \mathrm{~mm} \times 100 \mathrm{~mm} \times 2 \mathrm{~mm}$. The total mass of the PCB specimen was $51.09 \mathrm{~g}$. The boundary conditions of the PCB consist of a total of four holes for M3 screws. The solder columns of $80 \mathrm{~Pb} / 20 \mathrm{Sn}$ were wound with a reinforced copper ribbon to increase their mechanical safety under vibration or thermal cycling environments. They were then soldered on the PCB surface and package using a eutectic solder of $\mathrm{Sn63/Pb37.} \mathrm{These} \mathrm{solder} \mathrm{materials} \mathrm{have} \mathrm{heritages} \mathrm{for} \mathrm{space}$ usage. The specifications of the CCGA624 package are summarized in Table 3.

3.2. Description of Fatigue Test. Figure 6(a) shows a test setup for fatigue tests of PCB specimens under random vibration. The heat sinks, formed of aluminum 6061-T6, were integrated on each PCB specimen shown in Figure 5 to apply an initial compressive static load on the thermal pad located between the heat sink and PCB, as shown in Figure 6(b). Figure 6(c) shows an exploded view of the specimen assembly. The compression ratios of the pads were controlled by adjusting the height of the mechanical interface of the heat sink. Therefore, the height of the mechanical interface corresponding to a $10 \%$ compression ratio was $0.4 \mathrm{~mm}$ higher than that corresponding to a 50\% ratio, considering the pad thickness of $1 \mathrm{~mm}$. Here, the compression ratios of the pads for each specimen were controlled by adjusting the thickness of the heat sink. In the tests, we defined CG0, CG10, and CG50 specimens, which correspond to the thermal pads with compression ratios of $0 \%, 10 \%$, and $50 \%$, respectively. In case of CG10, two specimen sets of CG10A and CG10B were used for comparison of crack propagation rate on the solder joints depending on time. All specimens were exposed to random vibration in the $z$-axis until the test equipment detected the fracture on the solder joint, but the CG10B specimen was disassembled from the test set-up after 1-hour excitation for comparison of the crack propagation rate on the solder joints with that on CG10A. In this study, the vibration tests along the $x$ - and $y$-axes of the PCB specimens were not conducted. This was because the major failure mechanism of the solder joint occurred, which is the bending behavior of the PCB due to the vibration excitation along the $z$-axis, as verified in the previous studies [19-22].

The random vibration was implemented using an electrodynamic shaker (LDS V8, Brüel \& Kjær Co.). In the tests, only one accelerometer was attached on the fixture to monitor the input level of random vibrations during the test. This was because there was insufficient space on the four specimen assemblies for the attachment of the accelerometers, due to the presence of the heat sink. In situ resistance monitoring was performed to measure the time to failure of each package during the tests. For ease of resistance measurement, daisychain circuits were applied on the specimen packages, which made the solder joints to be connected in series, as shown in Figure 7. A data acquisition equipment (NI-9219, National Instruments Co.) was used to monitor the resistance of each package at a speed of 2 samples/sec. The initial resistance value of each package was set to approximately $5.2 \Omega$ considering the measurement error range of the equipment. In the 
TABLE 1: Properties of THERM-A-GAP G579 thermal gap pad [17].

\begin{tabular}{|c|c|c|c|}
\hline \multicolumn{2}{|l|}{ Typical properties } & Value & Test method \\
\hline \multicolumn{2}{|l|}{ Standard thicknesses $(\mathrm{mm})$} & $0.5 \sim 5.0$ & ASTM D374 \\
\hline \multicolumn{2}{|l|}{ Specific gravity } & 2.9 & ASTM D792 \\
\hline \multicolumn{2}{|l|}{ Hardness (Shore 00) } & 30 & ASTM D2240 \\
\hline \multirow{4}{*}{ Compression ratio (\%, at various pressures) } & At $34 \mathrm{kPa}$ & 22 & \multirow{4}{*}{ ASTM C165 MOD } \\
\hline & At $69 \mathrm{kPa}$ & 33 & \\
\hline & At $172 \mathrm{kPa}$ & 55 & \\
\hline & At $345 \mathrm{kPa}$ & 68 & \\
\hline \multicolumn{2}{|l|}{ Continuous use temperature $\left({ }^{\circ} \mathrm{C}\right)$} & -55 to 200 & - \\
\hline \multicolumn{2}{|c|}{ Thermal impedance $\left({ }^{\circ} \mathrm{C} \cdot \mathrm{cm}^{2} / \mathrm{W}\right.$, at $69 \mathrm{kPa}$, at $1 \mathrm{~mm}$ thickness $)$} & 4.5 & ASTM D5470 \\
\hline \multicolumn{2}{|l|}{ Coefficient of thermal expansion $\left(\mathrm{ppm} /{ }^{\circ} \mathrm{C}\right)$} & 150 & ASTM E831 \\
\hline \multicolumn{2}{|l|}{ Outgassing (\%, TML/CVCM) } & $0.19 / 0.06$ & - \\
\hline \multicolumn{2}{|l|}{ Shelf life (years from date of manufacture) } & 2 & - \\
\hline
\end{tabular}

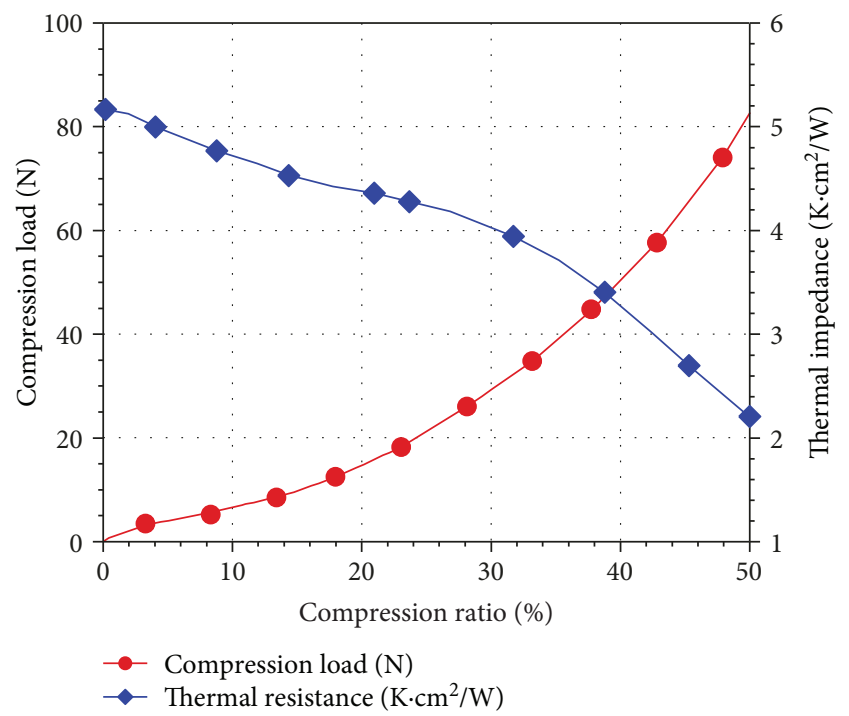

Figure 3: Compressive static load and thermal impedance for various compression ratios of the thermal gap pad.

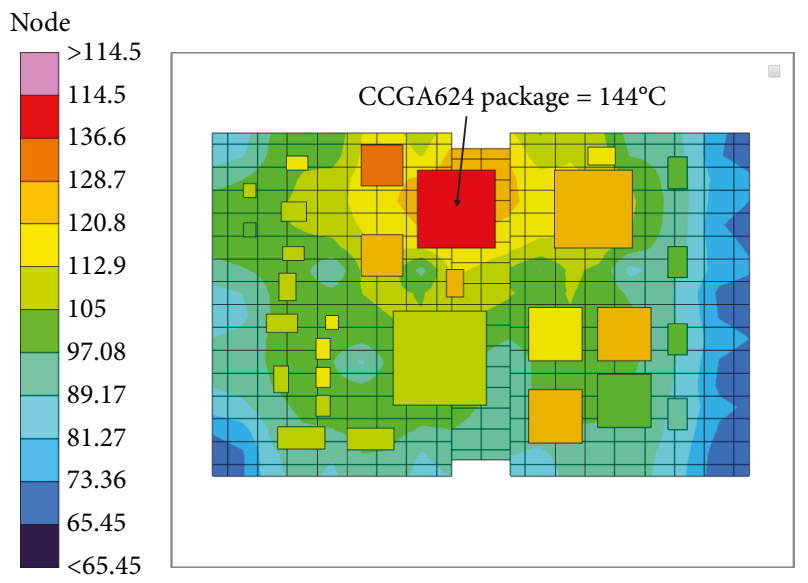

FIgURE 4: Temperature contour maps of CCGA624 packages with $0 \%$ compression ratio of the thermal gap pad.
TABle 2: Maximum temperatures of the CCGA624 package with various compression ratios of the thermal gap pad.

\begin{tabular}{lc}
\hline $\begin{array}{l}\text { Compression ratio of } \\
\text { thermal gap pad (\%) }\end{array}$ & $\begin{array}{c}\text { Maximum temperature of } \\
\text { CCGA624 package }\left({ }^{\circ} \mathrm{C}\right)\end{array}$ \\
\hline 0 & 144.5 \\
10 & 72.5 \\
50 & 69.7 \\
\hline
\end{tabular}

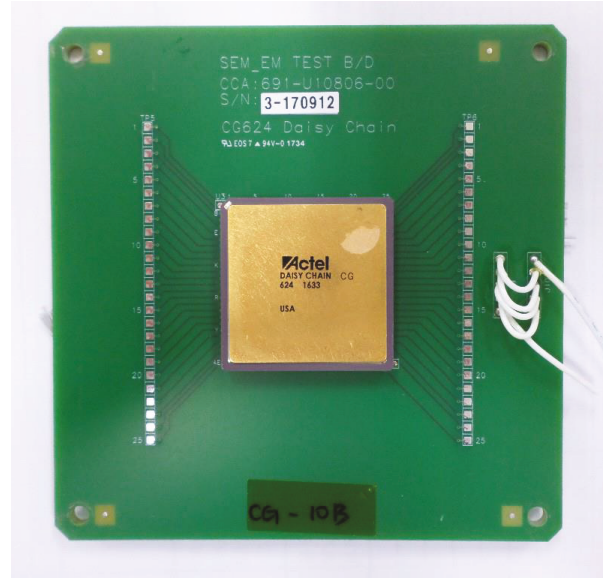

Figure 5: PCB specimen with CCGA624 package.

test, we defined the failure criteria on the solder joint as when the daisy-chain resistance value exceeded $10.5 \mathrm{k} \Omega$, which was the maximum measurement limit of the equipment. Table 4 shows the specification of the input random vibration for the specimens shown in Figure 6. The aim of the fatigue test was to relatively compare the fatigue lives of CCGA624 packages with various initial compressive loads of pads. Therefore, the input random vibration of the shaker was considered as the maximum available level of 28 grms.

\section{Validation of Test Results}

Figure 8 shows the test results of time histories for daisychain resistances for each specimen. The specimens were 
TABLE 3: Specifications of CCGA624 package [18].

\begin{tabular}{|c|c|c|}
\hline Item & & Value \\
\hline Manufacturer & & Microsemi Corporation \\
\hline \multicolumn{3}{|l|}{ Configuration } \\
\hline \multirow{2}{*}{ Column } & Composition & $80 \mathrm{~Pb} / 20 \mathrm{Sn}$ (with copper ribbon) \\
\hline & Dimension $(\mathrm{mm})$ & $2.21 \times 0.51$ (height $\times$ diameter $)$ \\
\hline \multirow{3}{*}{ Package } & Dimension & $32.5 \times 32.5 \times 2.25$ \\
\hline & Number of column pins & 624 \\
\hline & Lead pitch $(\mathrm{mm})$ & 1.27 \\
\hline Total weight $(\mathrm{g})$ & & 13.28 (including $2.36 \mathrm{~g}$ for solder columns) \\
\hline JEDEC Registration & & JEDEC MO-158 VAR BE-1 \\
\hline
\end{tabular}

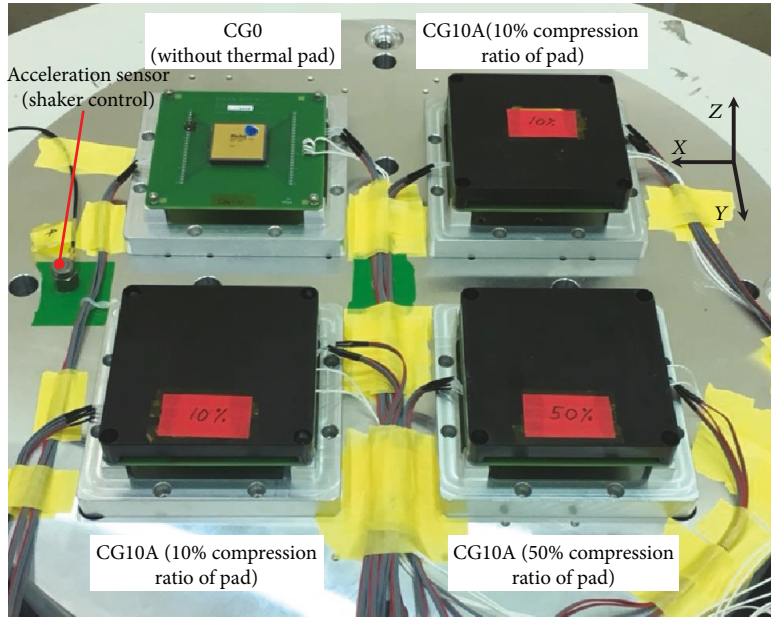

(a)
Heatsink (with various heights of mechanical I/F in each specimen)

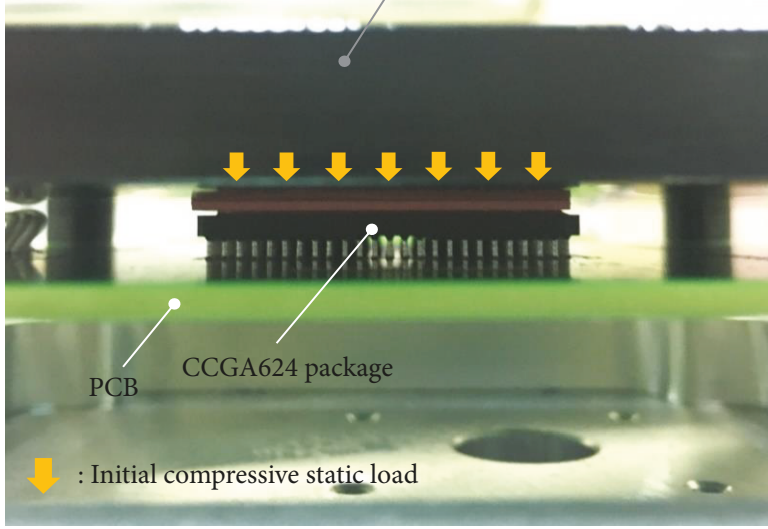

(b)

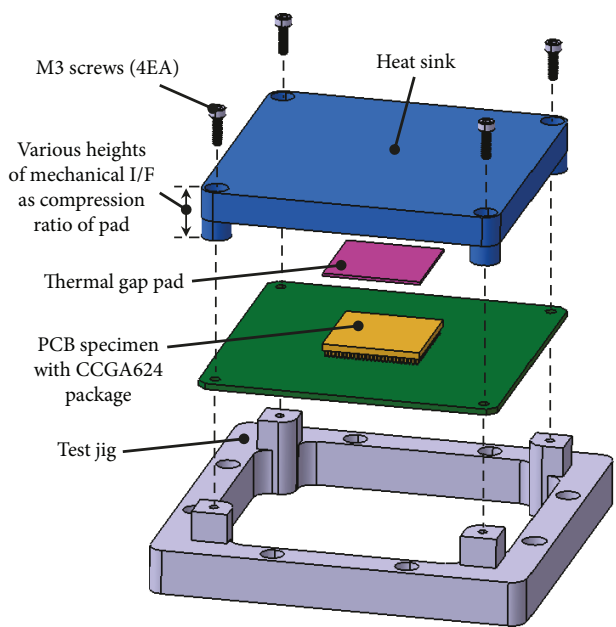

(c)

FIgURE 6: Random vibration fatigue test setup ((a) Overall view (b) Close-up view of the thermal gap pad (c) Exploded view).

exposed to the random vibration environment specified in Table 4. The resistance value of the CG0 specimen rapidly reached the $10.5 \mathrm{k} \Omega$ value defined as a failure of the solder joint after 5.38 minutes of excitation. This specimen was disassembled from the test set-up after 20 min because the package could be excessively damaged if the test was continued. 




FIgURE 7: Daisy-chain circuit for CCGA624 package.

TABLE 4: Specification of random vibration.

\begin{tabular}{lc}
\hline Frequency $(\mathrm{Hz})$ & PSD $\left(\mathrm{g}^{2} / \mathrm{Hz}\right)$ \\
\hline 20 & 0.404 \\
2000 & 0.404 \\
Overall & $28 \mathrm{grms}$ \\
\hline
\end{tabular}

Since the resistance values of the specimens with thermal pads were not varied during $20 \mathrm{~min}$, as shown in Figure 8, they were exposed to random vibration for $10 \mathrm{~h}$, with the exception of the CG10B specimen, which was disassembled after $1 \mathrm{~h}$ of testing, to compare the number of cracked solder joints with those of the other specimens with pads. However, their resistance variations were not observed until the end of the test.

Figures 9(a) and 9(b) show representative examples of metallographic microscope images of the fully and partially cracked solder joints of the CG0 specimen after the test, respectively. Figure 10 shows the total number of cracked solder joints obtained from the metallographic microscope inspections for each specimen. The CG0 specimen showed 73 fractured solder joints, including partially cracked ones during the 20 minutes of random vibration. However, the other three specimens also showed the cracks on solder joints, although their resistance values were not varied during the test. This is because the initial compressive static load of the pad maintained the electrical connection of the daisychain circuit despite the crack propagation on the solder joint. However, the number of fractured solder joints of specimens with thermal pads was much less than that without the pad, as shown in Figure 10. The CG10A specimen exposed to random vibration for 10 hours showed 26 fractured solder joints, which is approximately 2.8 times less than that of

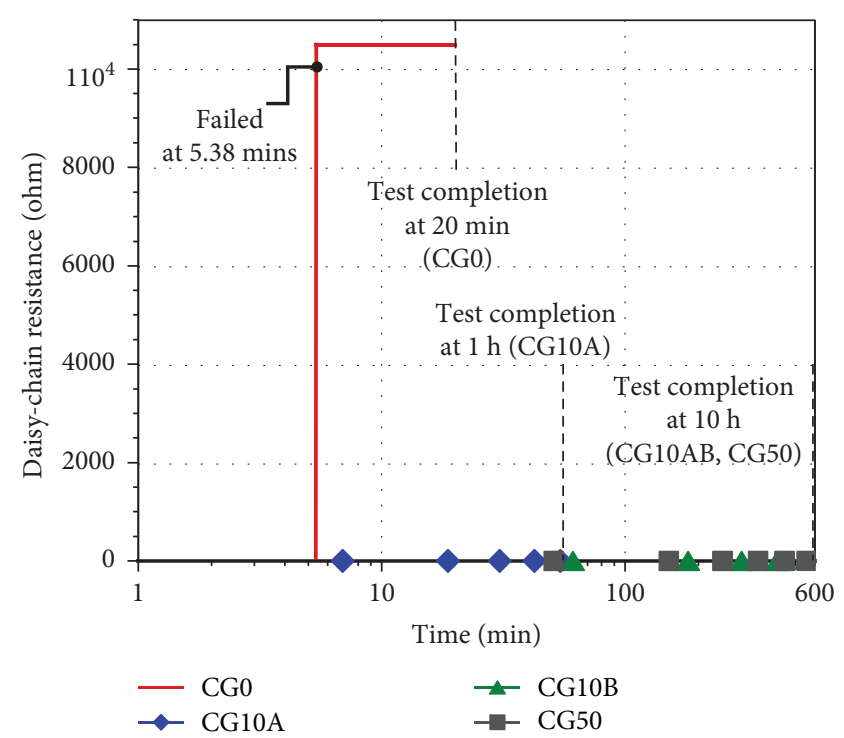

FIgURE 8: Time profiles of daisy-chain resistances for each specimen.

the CG0 specimen. In addition, 16 fractured solder joints, which is 1.63 times less than that of the CG10A specimen, were observed from the CG10B specimen during a 1-hour progress. These test results indicate that the crack propagation on the solder joint was initiated at some point within 1 hour of the test. Finally, the specimen case of CG50 showed 27 cracked solder joints during 10 hours of the test, as shown in Figure 10, which is a similar result as that obtained for the CG10A specimen.

These test results indicate that the initial compressive static load of the pad is more advantageous to guarantee a structural safety on the solder joint under a random vibration environment compared to that without a thermal pad. This is because the initial compression load of the pad applied on the package reduces the dynamic deflection of the PCB, which incurs stress on the solder joint under random vibration excitation. However, in the tests, the exact time to failure on the solder joints could not be observed from the PCB specimens with thermal pads due to the difficulty of failure detection on the solder joint under initial static load of the pad by daisychain resistance monitoring. Thus, we predicted the fatigue life on the solder joint of the tested specimens with and without the initial compressive static load of the pad through structural analyses.

\section{Numerical Fatigue Life Prediction on Solder Joint}

For fatigue life prediction of solder joints of tested specimens, under conditions of an initial compressive static load of the thermal pad in a random vibration environment, dynamic responses of these specimens were analyzed by structural analyses with the random vibration input profile specified in Table 4. In this study, the specimen assemblies under various boundary conditions on the PCB were also analyzed for prediction of the fatigue life of solder joints with varying eigenfrequencies of PCB. 


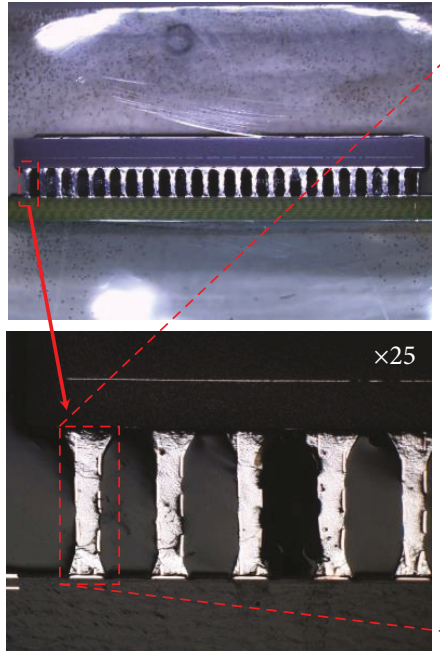

(a)

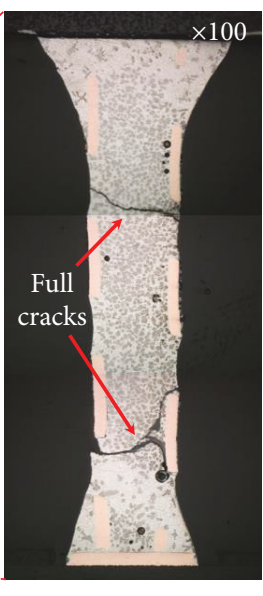

)
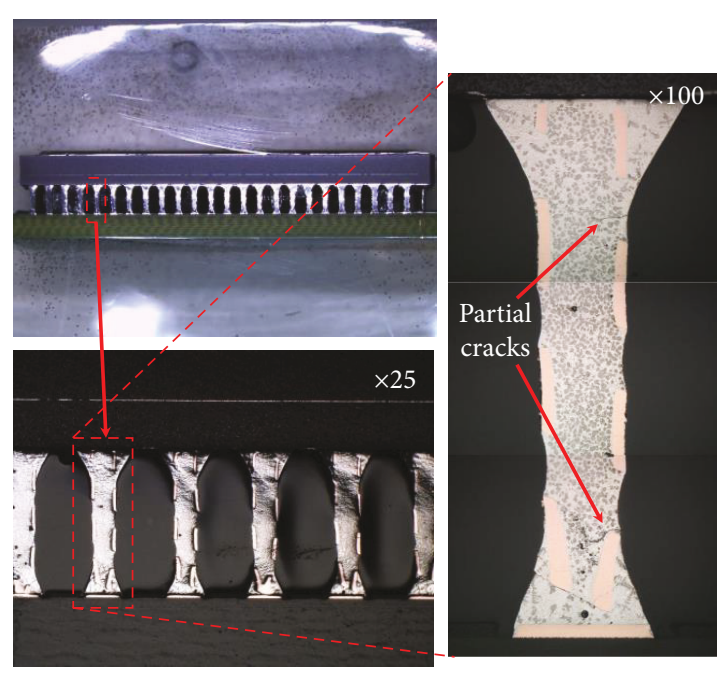

(b)

Figure 9: Representative metallographic microscope photographs of the solder joint for CCGA624 package ((a) Full crack, (b) Partial crack).
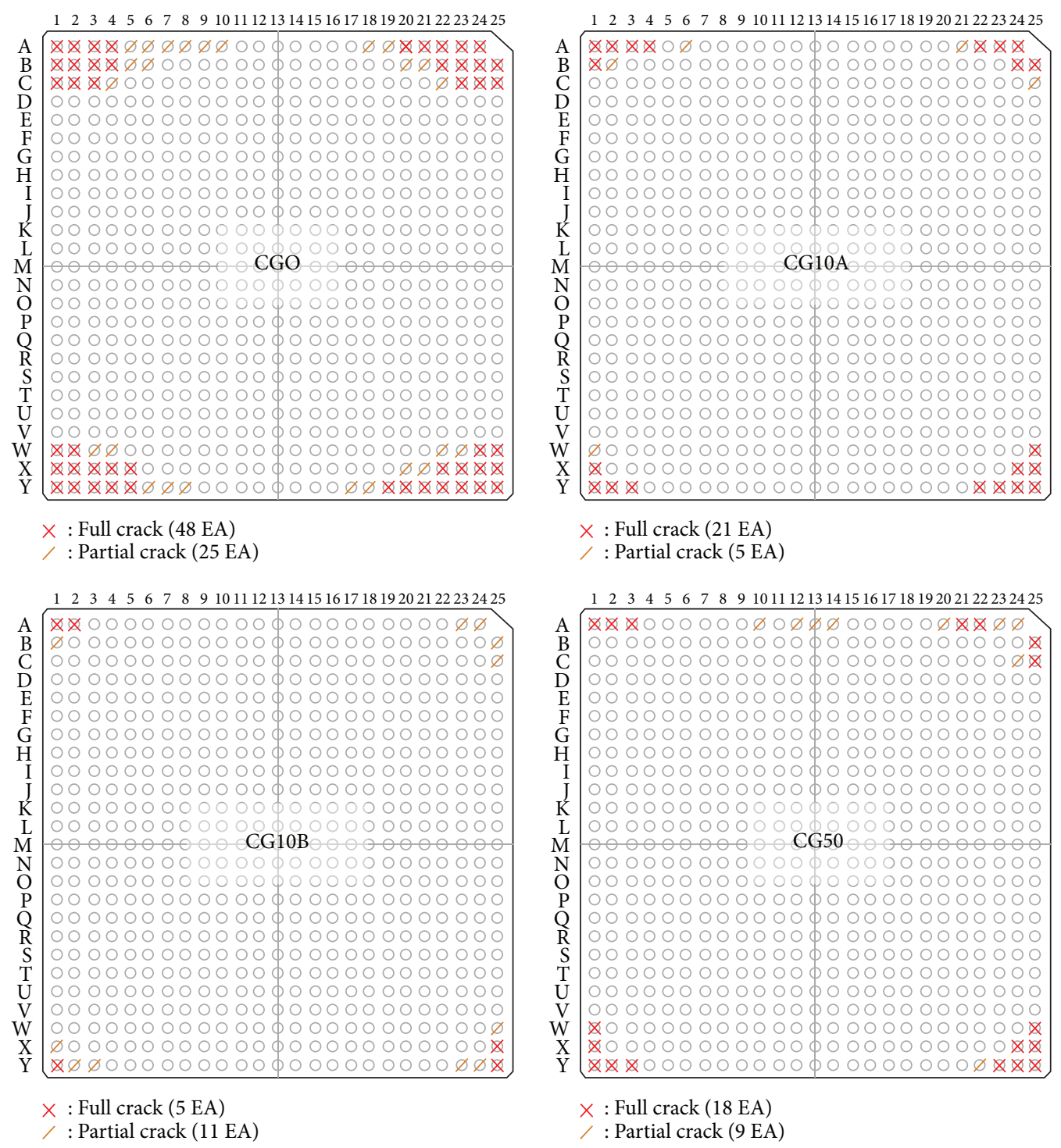

FIGURE 10: Location and number of cracked solder joints for each specimen. 




(a)

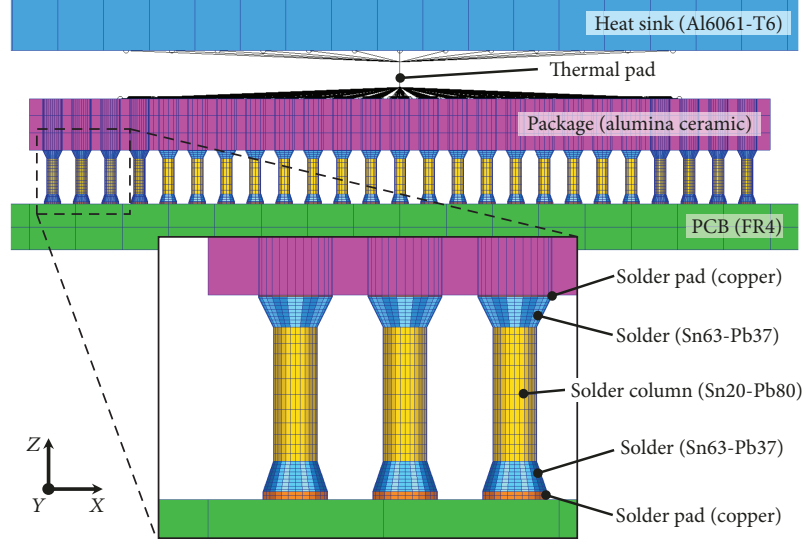

(b)

Figure 11: Configurations of FEM ((a) Overall view, (b) Close-up view of the thermal gap pad).

TABLE 5: Material properties for structural analyses.

\begin{tabular}{lcccc}
\hline Item & Material & Young's modulus $(\mathrm{MPa})$ & Poisson's ratio & Density $\left(\mathrm{kg} / \mathrm{m}^{3}\right)$ \\
\hline Column lead & $80 \mathrm{~Pb} / 20 \mathrm{Sn}$ & 20,000 & 0.36 & 10,200 \\
Solder & $37 \mathrm{~Pb} / 63 \mathrm{Sn}$ & 29,367 & 0.36 & 8490 \\
Solder pad & Copper & 128,000 & 0.3 & 8940 \\
Package & Alumina ceramic $\left(\mathrm{Al}_{2} \mathrm{O}_{3}\right)$ & 215,000 & 0.3 & 3620 \\
PCB & FR-4 & 18,600 & 0.13 & 1850 \\
Heat sink & Al6061-T651 & 68,900 & 0.33 & 2700 \\
\hline
\end{tabular}

To calculate the fatigue life of solder joints, we used a critical strain theory based on an empirical formula, because the stress applied to solder joints is perpendicular to the strain of the PCB adjacent to it [23]. The critical PCB strain, $\epsilon_{\mathrm{c}}$, which corresponds to the maximum principal in-plane strain of PCB from the area adjacent to the critical solder joint, is defined as

$$
\epsilon_{\mathrm{c}}=\frac{\zeta}{C \sqrt{L}}
$$

where $C$ is the electronic packaging-type constant derived from the multiple vibration tests and FEM-based studies, and $L$ stands for the length of the package. The value of $\zeta$ can be calculated using the equation presented in the IPCWP-011 guideline [24], as follows:

$$
\zeta=\sqrt{\frac{2.35}{t}} \times\{1900-300 \times \log (\dot{\varepsilon})\},
$$

where the $t$ and $\dot{\varepsilon}$ are the thickness and the strain rate of the PCB under vibration, respectively. The values of $\epsilon_{\mathrm{c}}$ calculated using (2) were further used to predict the number of cycles, $N_{\mathrm{f}}$, to reach the failure of the solder joint as follows:

$$
N_{\mathrm{f}}=N_{\mathrm{c}}\left(\frac{\epsilon_{\mathrm{c}}}{\epsilon_{p_{\max }}}\right)^{b}
$$
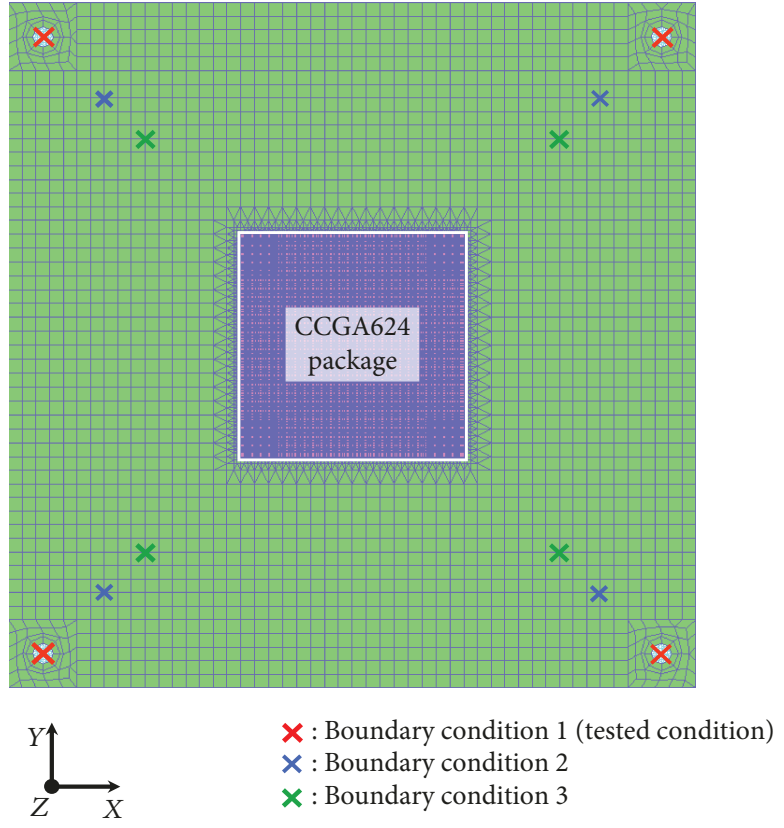

FiguRe 12: Various boundary conditions for structural analysis.

where $N_{\mathrm{c}}$ is the critical number of cycles to reach failure, which corresponds to 20 million cycles for random vibration, as proposed by the Steinberg, and $b$ is the fatigue exponent of solder material obtained from the stress-life cycle $(\mathrm{S}-\mathrm{N})$ curve. In case of the maximum in-plane PCB strain, $\epsilon_{\max }$, 


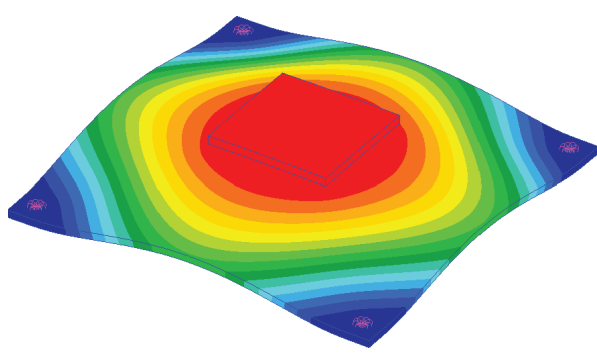

(a)



(b)

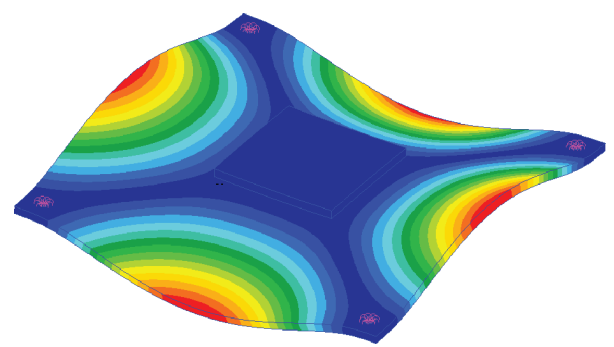

(c)

FIgure 13: Modal analysis results for PCB ((a) 1st mode: $370 \mathrm{~Hz}$, (b) 2nd Mode: $819.09 \mathrm{~Hz}$, (c) 3rd Mode: $1180.1 \mathrm{~Hz}$ ).

the 2-sigma value of the root mean square (RMS) strain was used. This value was chosen using a simple approximation method [5], which simplifies the calculation of fatigue life under random vibration based on a threeband technique with Gaussian probability distribution. The RMS value of in-plane principal strain, $\varepsilon_{p_{\max }}$, can be calculated as follows [25]:

$$
\varepsilon_{p_{\max }}=3 \times\left(\frac{\varepsilon_{x_{\mathrm{rms}}}+\varepsilon_{y_{\mathrm{rms}}}}{2}+\sqrt{\left(\frac{\varepsilon_{x_{\mathrm{rms}}}-\varepsilon_{y_{\mathrm{rms}}}}{2}\right)^{2}+\left(\varepsilon_{x y_{\mathrm{rms}}}\right)^{2}},\right.
$$

where $\varepsilon_{x_{\text {rms }}}$ and $\varepsilon_{y_{\text {rms }}}$ stand for the RMS in-plane normal strains in $x$ and $y$ directions, respectively, and $\varepsilon_{x y_{\text {rms }}}$ is the RMS in-plane shear strain.

Figures 11(a) and 11(b) show the constructed specimen assembly with the thermal pad finite element model (FEM) for the random vibration analysis shown in Figure 6. This model reflects the details of the package, solder, solder column, and solder pad configurations, as shown in Figure 11(a). The thermal pad was simply modeled using a CBUSH element to incorporate its stiffness and structural damping ratio in accordance with the pad compression ratio. The pad is connected with the PCB and heat sink using RBE2 elements, as shown in Figure 11(b). The model consists of 2,011,056 nodes, 302,860 CPENTA elements, 1,627,353 CHEXA elements, 1 CBUSH element, and 18 RBE2 elements. In addition, three translational degrees of freedom (DOF) were constrained on each screw hole of PCB and heat sink. Table 5 summarizes the material properties used in the analysis. To predict the fatigue life on the solder joint of specimen assemblies with various locations of constraint conditions on the PCB, we defined three analysis cases in accordance with the locations of the $3-\mathrm{DOF}$ constraints, as shown in
Figure 12. Here, case 1 corresponds to the PCB having only boundary condition 1 applied, which is similar to the test conditions shown in Figure 6. Case 2 corresponds to the PCB having boundary conditions 1 and 2 applied. Finally, case 3 corresponds to the PCB having boundary conditions 1 and 3 applied.

To increase the reliability of the analysis results, the FEM correlation of a bare PCB was performed. The effectiveness of the correlation approach using bare PCB has been validated by the previous study of Park et al. [26]. This was because the accelerometer attachment for the specimen assembly with the thermal gap pad was difficult to achieve, due to the presence of the heat sink and the pad assembled on the package. The figure below shows power spectral density (PSD) responses at the center of the bare PCB, obtained from the analysis and test. The 1st eigenfrequency from the analysis results was $347.3 \mathrm{~Hz}$, with a difference of $0.66 \%$ from the measured value. In addition, the root mean square (RMS) acceleration was 115.8 grams, which was in good agreement with the measured value because the difference was only $1.61 \%$. The FEM of the PCB with the CCGA624 package was constructed based on the correlation results of the bare PCB.

Figure 13 shows the results of the modal analysis, with eigenfrequencies and mode shapes of the tested CG0 specimen. The global bending mode of PCB is observed along the out-of-plane direction at the first eigenfrequency of $370 \mathrm{~Hz}$. This is the most dominant mode for the mechanical reliability of the solder joint due to the largest relative displacement between the PCB and the package. Figure 14 shows the variation of the first eigenfrequencies of $\mathrm{PCB}$ with various pad compression ratios in each case. The results indicate that the first eigenfrequency becomes higher as the compression ratio of the pad increases. A 22.65\% increase in PCB eigenfrequency can be achieved at a $50 \%$ ratio of the pad. In addition, the same effect was also observed for cases 2 and 3. 




FIGURE 14: 1st eigenfrequencies of PCB for the compression ratio of the thermal gap pad in each case.

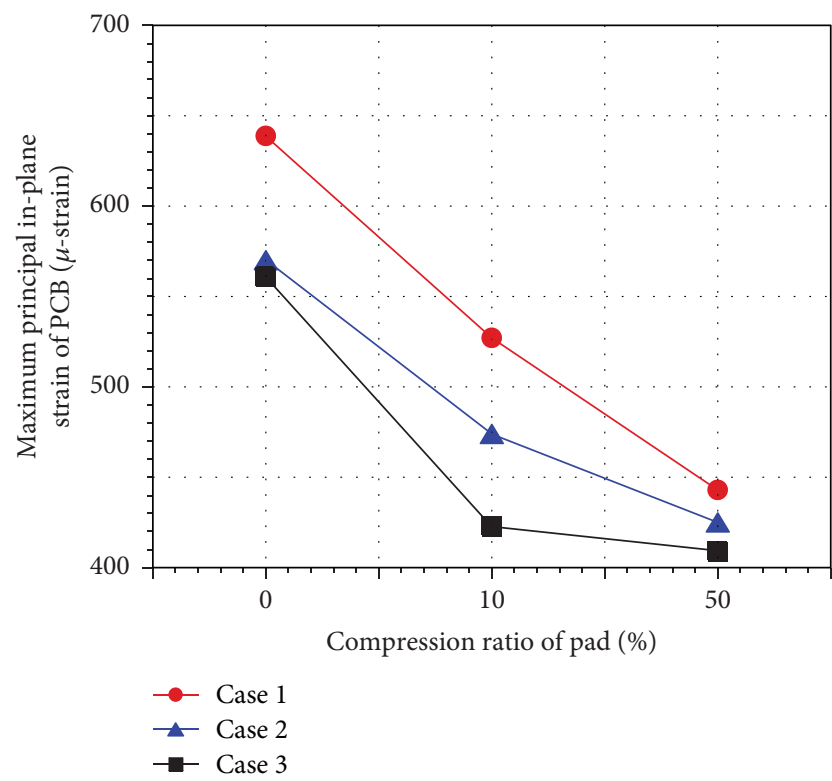

Figure 15: Maximum principal in-plane strain of PCB in accordance with compression ratio of the thermal gap pad in each case.

This is because the stiffness of the compressed thermal pad contributes to the increase in the equivalent stiffness of the PCB assembly.

Figures 15 shows the results of random vibration analysis, demonstrating the maximum values of the PCB inplane principal strain according to the compression ratio of the pad in each case, respectively. The results indicate that the maximum strain of PCB decreases with an increasing compression ratio of the pad. For example, in case 1, the maximum strain of the $639 \mu$-strain occurred from the PCB at the $0 \%$ compression ratio of the thermal pad. By

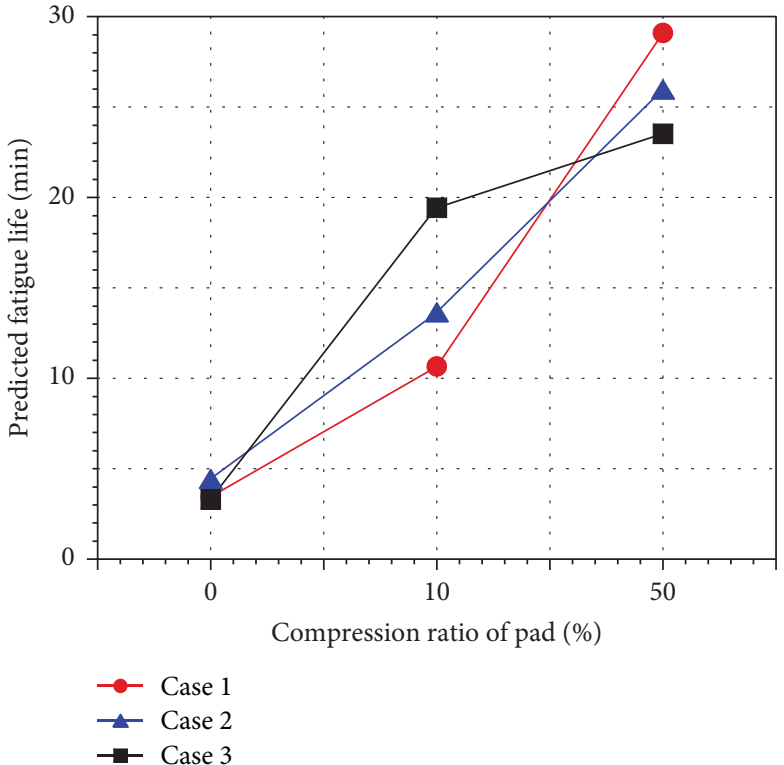

FIgURE 16: Fatigue life on solder joint for CCGA624 package with respect to the fatigue life in each case.

compressing the pad at ratios of $10 \%$ and $50 \%$, the maximum strains become 527 and $443 \mu$-strains, or $17.53 \%$ and $30.67 \%$ lower compared with those at the $0 \%$ ratio, respectively. This is due to the reduction in PCB displacement in accordance with its increased eigenfrequency with the pad initial compressive load, as shown in Figure 14.

Figure 16 shows the fatigue life on the solder joint predicted based on the maximum PCB strains in each case shown in Figure 14. In case 1, the predicted time to failure of a solder joint with the thermal pad at a $0 \%$ compression ratio is 3.43 minutes. This is similar to the fatigue test results shown in Figure 8, although there is a 1.95-minute difference between the prediction and the test. Thus, we concluded that the predicted time to reach the failure of the solder joint agrees well with the test results. In addition, this time for the thermal pad at the compression ratio of $10 \%$ is 10.67 minutes, which is 3.11 times larger than that of the $0 \%$ ratio. This indicates that the crack of the solder joint might be initiated at that time during the test. Finally, the time to reach the failure of the solder joint at the $50 \%$ ratio is 29.1 minutes, which is 8.49 times greater than that of the $0 \%$ ratio. These results indicate that the fatigue life on the solder joint under random vibration can be increased as the initial compressive static load of the thermal pad increases. In addition, we also confirmed that the fatigue life on the solder joint with the thermal pad also increases even if the eigenfrequency of PCB is higher than the tested one. However, the predicted fatigue lives of the solder joints at a pad compression ratio of $50 \%$ in cases 2 and 3 were $10.8 \%$ and $19.1 \%$ smaller than that in case 1 , respectively, although their in-plane PCB strain responses decreased, as shown in Figure 15. This was due to the acceleration of the fatigue cycle of the solder joints in accordance with the increase in the eigenfrequency of the PCB. These results indicate that this adverse effect should be also considered when applying the pad to the electronics. 


\section{Conclusions}

This paper investigates the influence of initial compressive static load for a thermal gap pad, from the viewpoint of the solder joint fatigue life in a random vibration environment. For experimental validation, we manufactured the PCB specimens with CCGA624 packages with the various compression ratios of thermal pads $(0 \%, 10 \%$, and $50 \%)$. These samples were exposed to the random vibration excitation until the daisy-chain resistance of each specimen exceeded the failure criteria. The test results indicated that the initial compressive static loads of pads affected the failure time of the solder joints. However, in the tests, the exact failure time of solder joints could not be observed through the daisychain resistance monitoring, because the initial static load of the pad maintained the electrical connection of the daisy-chain circuit, even if the solder joint was cracked during the test. Therefore, the solder joint fatigue life for the tested specimens was predicted through the structural analyses. The analysis results indicated that the presence of a compressed thermal pad could increase the fatigue life on the solder joint due to the restriction of the dynamic displacement of PCB under random vibration.

\section{Data Availability}

All the data supporting the results were shown in the paper and can be applicable from the corresponding author.

\section{Conflicts of Interest}

The authors declare that they have no competing interests.

\section{Acknowledgments}

This research was supported by the National Research Foundation of Korea (NRF, NRF-2018R1D1A1B05047385) and funded by the Ministry of Education (MoE).

\section{References}

[1] R. Ghaffarian and N. P. Kim, "Ball grid array reliability assessment for aerospace applications," Microelectronics Reliability, vol. 39, no. 1, pp. 107-112, 1999.

[2] G. V. Chary, E. Habtour, and G. S. Drake, "Improving the reliability in the next generation of US army platforms through physics of failure analysis," Journal of Failure Analysis and Prevention, vol. 12, no. 1, pp. 74-85, 2012.

[3] R. A. Amy, G. S. Aglietti, and G. Richardson, "Reliability analysis of electronic equipment subjected to shock and vibration - a review," Shock and Vibration, vol. 16, no. 1, 59 pages, 2009.

[4] J. J. Wijker, Spacecraft Structures, Springer, 2008.

[5] D. S. Steinberg, Vibration Analysis for Electronic Equipment, John Wiley \& Sons Inc., New York, NY, USA, 3rd edition, 2000.

[6] Y. K. Kim and D. S. Hwang, "PBGA packaging reliability assessments under random vibrations for space applications," Microelectronics Reliability, vol. 55, no. 1, pp. 172-179, 2015.
[7] J. Jang, G. Jang, J. Lee, Y. Cho, and Y. Cinar, "Fatigue life estimations of solid-state drives with dummy solder balls under vibration," International Journal of Fatigue, vol. 88, pp. 4248, 2016.

[8] R. V. Uppalapati, K. Leiser, M. V. Sickle, S. Parupalli, and V. Vasudevan, "Board design influence on BGA mechanical reliability," in 2007 Proceedings 57th Electronic Components and Technology Conference, pp. 1788-1795, Reno, NV, USA, 2007.

[9] D. Yu, H. Lee, and S. Park, "Reliability assessment of preloaded solder joint under thermal cycling," Journal of Electronic Packaging, vol. 134, no. 4, article 041008, 2012.

[10] “THERM-A-GAP G579 reliability test report," TR 1024 EN 11/07, CHOMERICS Division of Parker Hannifin Corporation, 2007.

[11] K. Bruzda, "Stress minimization during deflection of thermally conductive gap pads," in Twenty-Third Annual IEEE Semiconductor Thermal Measurement and Management Symposium, pp. 136-143, San Jose, CA, USA, 2007.

[12] T. C. Chiu, D. Edwards, and M. Ahmad, "Ball grid array solder joint reliability under system-level compressive load," IEEE Transactions on Device and Materials Reliability, vol. 10, no. 3, pp. 324-337, 2010.

[13] Y. J. Lee, "Thermo-mechanical properties of high performance thermal interface gap filler pads," in 2010 12th IEEE Intersociety Conference on Thermal and Thermomechanical Phenomena in Electronic Systems, pp. 1-8, Las Vegas, NV, USA, 2010.

[14] S. K. Ray, H. Quinones, S. Iruvanti, E. Atwood, and L. Walls, "Ceramic column grid array (CCGA) module for a high performance work station application," in 1997 Proceedings 47th Electronic Components and Technology Conference, pp. 319-324, San Jose, CA, USA, 1997.

[15] R. Ghaffarian, "CCGA packages for space applications," Microelectronics Reliability, vol. 46, no. 12, pp. 2006-2024, 2006.

[16] R. Ramesham, "Reliability of ceramic column grid array (CCGA717) interconnect packages under extreme temperatures for space applications," Journal of Microelectronics and Electronic Packaging, vol. 7, no. 1, pp. 16-24, 2010.

[17] http://www.parker.com/portal/site/PARKER/menuitem.223a 4a3cce02eb6315731910237ad1 ca/?vgnextoid=8fc0d7196965 e210VgnVCM10000048021 dacRCRD\&vgnextfmt=default.

[18] https://www.microsemi.com/document-portal/doc_view/ 129892-ac190-ceramic-column-grid-array-application-note.

[19] Y. Cinar, J. Jang, G. Jang et al., "Failure mechanism of FBGA solder joints in memory module subjected to harmonic excitation," Microelectronics Reliability, vol. 52, no. 4, pp. 735-743, 2012.

[20] K. P. Subramanya, J. K. Pandit, C. S. Prasad, and M. R. Thyagaraj, "Vibration analysis study of spacecraft electronic package: a review," International Journal of Science, Engineering and Technology Research, vol. 3, no. 3, pp. 503-507, 2014.

[21] Q. J. Yang, Z. P. Wang, G. H. Lim, J. H. L. Pang, F. F. Yap, and R. M. Lin, "Reliability of PBGA assemblies under out-of-plane vibration excitations," IEEE Transactions on Components and Packaging Technologies, vol. 25, no. 2, pp. 293-300, 2002.

[22] M. Grieu, G. Massiot, O. Maire et al., "Durability modelling of a BGA component under random vibration," in EuroSimE 2008 - International Conference on Thermal, Mechanical and 
Multi-Physics Simulation and Experiments in Microelectronics and Micro-Systems, pp. 1-8, Freiburg im Breisgau, Germany, 2008.

[23] https://www.dfrsolutions.com/.

[24] IPC-WP-011, Guidance for Strain Gage Limits for Printed Circuit Assemblies, Association Connecting Electronics Industries, 2011.

[25] J. De Clerck and D. S. Epp, Rotating Machinery, Hybrid Test Methods, Vibro-Acoustics \& Laser Vibrometry, vol. 8, The Society for Experimental Mechanics Inc., Cham, Switzerland, 2016.

[26] T. Y. Park, J. C. Park, and H. U. Oh, "Evaluation of structural design methodologies for predicting mechanical reliability of solder joint of BGA and TSSOP under launch random vibration excitation," International Journal of Fatigue, vol. 114, pp. 206-216, 2018. 




\section{Enfincering}
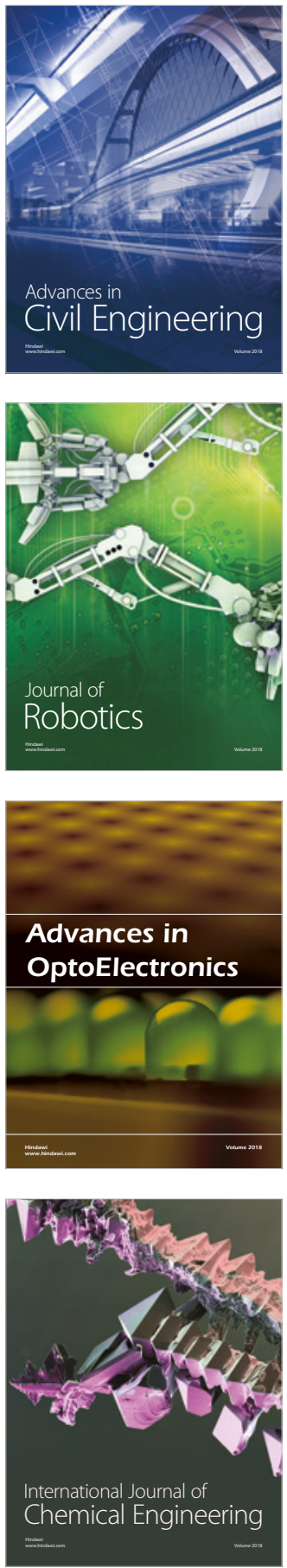

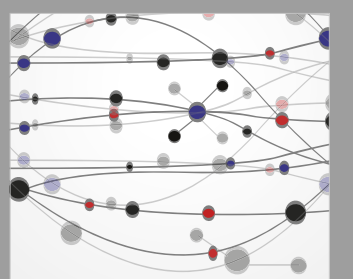

\section{Rotating \\ Machinery}

The Scientific World Journal

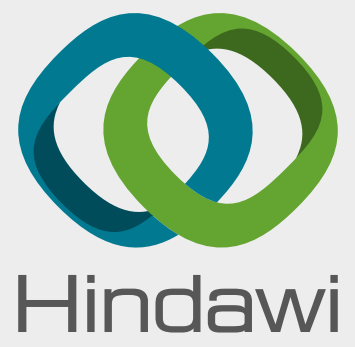

Submit your manuscripts at

www.hindawi.com
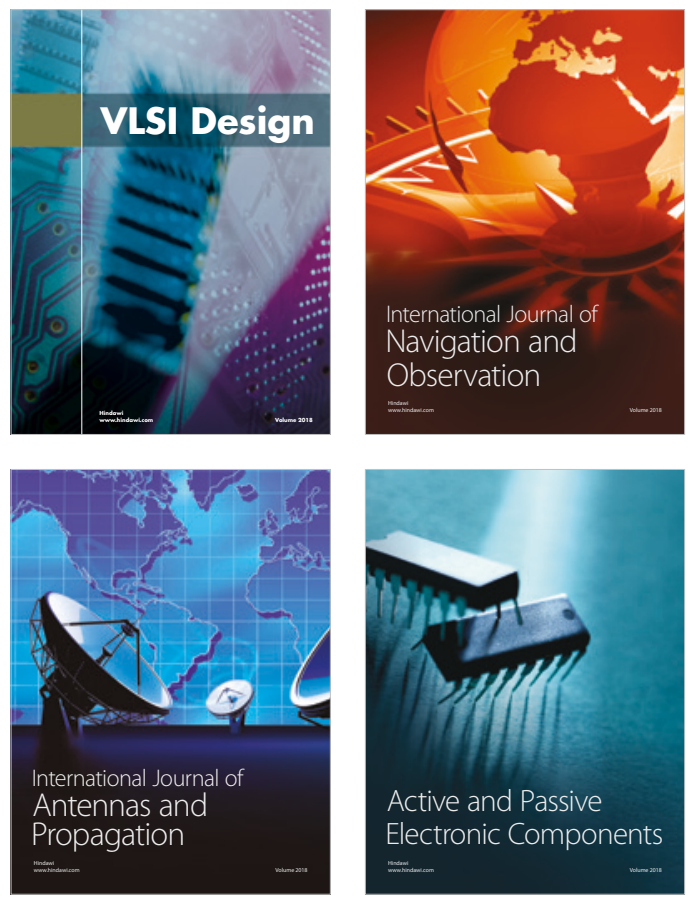
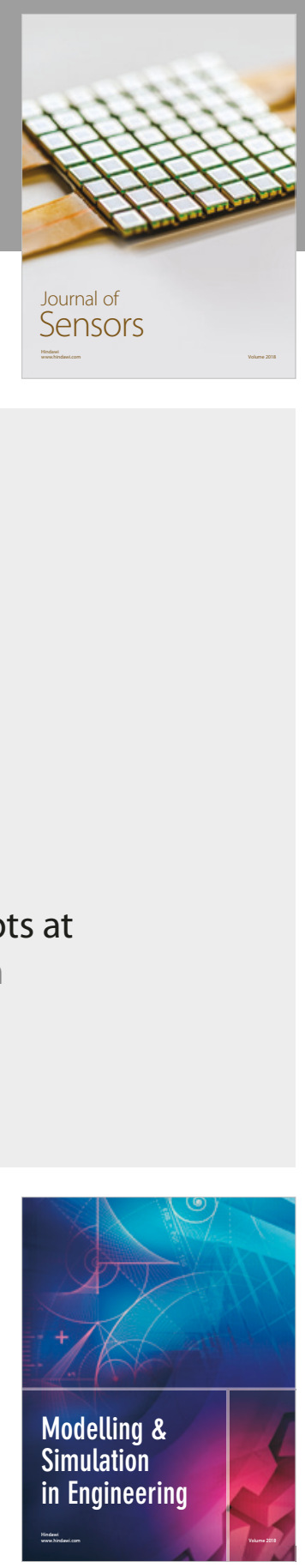

\section{Advances \\ Multimedia}
